Research Article

\title{
Calculation and Analysis of DC Magnetic Bias Current of Urban Main Transformer under the Action of Stray Current
}

\author{
Weili Wu (D), Wenmei Chen, and Lei Li \\ School of Electrical and Control Engineering, Xi'an University of Science \& Technology, Xi'an 710054, Shaanxi, China \\ Correspondence should be addressed to Weili Wu; wwllxm1999@xust.edu.cn
}

Received 28 April 2021; Accepted 1 July 2021; Published 12 July 2021

Academic Editor: Sang-Bing Tsai

Copyright (c) 2021 Weili Wu et al. This is an open access article distributed under the Creative Commons Attribution License, which permits unrestricted use, distribution, and reproduction in any medium, provided the original work is properly cited.

\begin{abstract}
The stray current generated by subway running into the ground makes the main transformer in the urban area in a direct current (DC) bias state. First, the mathematical model of the metro stray current field is established and the Galerkin finite element method is applied to calculate the model. Then, the dynamic model of the stray current-induced geoelectric field under different working conditions is established by using ANSYS software, and the three-dimensional numerical simulation study of the stray current-induced geoelectric field of the subway is carried out. Finally, taking the Urumqi subway in Xinjiang as an example, the stray current-induced geoelectric field is calculated and simulated, and the correctness of the model is verified by comparing with the measured data of DC magnetic bias in the urban substation. The research can provide useful reference for the calculation and treatment of DC bias of the main transformer in the urban area under the action of stray current.
\end{abstract}

\section{Introduction}

There are three main causes of DC bias in a transformer: HVDC system operating in monopole mode [1-3], geomagnetic induction current (GIC) [4-6], and stray current generated by subway operation [7-10]. The safe operation of a transformer is the basis of power grid safe power supply, and the above three reasons will cause different degrees of DC bias of the transformer. It will damage the transformer body and even endanger the safe operation of the whole power grid if the transformer is in the DC bias state for a long time.

At present, most of the research studies are focused on the theoretical calculation, analysis, and treatment under the action of monopole earth mode operation of HVDC transmission or on GIC. Pan et al. have devoted themselves to the theoretical derivation and numerical analysis of the grounding problem of the horizontal layered soil, and based on the separation of the variable method and the boundary conditions of the full space layered soil, the general theoretical expression of Green's function of any layer in the whole space is obtained [11]. Ma et al. [12] put forward the method of an equivalent resistance network, which avoids the tedious underground current field and greatly simplifies the calculation process. However, it is not easy to determine the values of the pole self-resistance and the interelectrode coupling resistance. Although there are few studies on DC magnetic bias of the transformer under the action of metro stray current, some achievements have been made. References [13-15] proposed a multilevel network model including the system of current drainage net, established the analytical formula for calculating the metro stray current considering the system of drainage net, and obtained the distribution of stray current. The calculation model of the stray current was obtained by dividing the system according to the mathematical principle, and the influence of the resistance between the track and the ground and the resistance characteristics of the ground itself on the stray current were discussed. The distribution of the track current and drainage network current is obtained by solving the problem. The abovementioned documents have laid a solid foundation for the analysis of the stray current-induced geoelectric field in subway operation, but they are all based on the simulation analysis under ideal conditions. The actual operation is often more complex, and the underground resistance distribution is discrete and irregular. Therefore, computer simulation is very necessary. Yu 
et al. established the model of metro stray current by using CDEGS software and analyzed the characteristics of current distribution under different working conditions. This simulation method makes up for the defect that the analytical method is difficult to apply considering complex parameters and provides a new way to study stray current [16]. In reference [17], according to the changes in the train speed, position, size of locomotive current, and so on, with time, based on the static stray current model and traction calculation of track-drainage network-buried metal-earth structure, a stray current dynamic distribution model based on time-position-current drawing change under bilateral power supply mode is designed, and the model is calculated and solved to realize three-dimensional simulation. By analyzing the dynamic distribution of the stray current and rail potential under different conditions, the dynamic stray current and rail potential distribution on a specific spot with time is obtained.

In this paper, the dynamic model of stray current-induced geoelectric field under different working conditions is established by using ANSYS software, and the integrated model of "stray current-geoelectric field-magnetic bias DC" is constructed. Taking Urumqi subway in Xinjiang as an example, the stray current-induced geoelectric field is calculated and analyzed. Finally, the magnetic bias current of the main transformer in the urban area is obtained. The correctness of the model is verified by comparing with the measured data. The research can provide useful reference for the calculation and treatment of DC bias of the main transformer in the urban area under the action of stray current.

\section{Integrated Model of "Stray Current- Geoelectric Field-Magnetic Bias DC"}

The locomotive is driven by DC current. The locomotive obtains current from the positive pole of the traction substation, and the current returns to the negative pole of the traction station through a running rail [18]. Due to the fact that the rail cannot be completely insulated from the ground, stray current will be formed in the process of metro operation. In the process of the stray current flowing to the earth, the current will pass through the drainage network laid under the rail and then through the buried metal. The current has a certain corrosive effect on the rail and the buried metal. Figure 1 shows the stray current flow path of multiple trains running at the same time.

After the stray current enters the earth, because of its fluidity, the current continuously flows to the deep soil. When the stray current flows through the soil with different resistivities, it forms different potentials on the earth surface at different positions [19]. The stray current can be treated as a point source because the value of the stray current entering the ground is very small. From Maxwell's equations, the stray current in soil satisfies the following field equation:

$$
\begin{cases}\nabla^{2} V=0, & \text { without current source, } \\ \nabla^{2} V=-\frac{\partial \rho_{v}}{\partial t}, & \text { including current source, }\end{cases}
$$

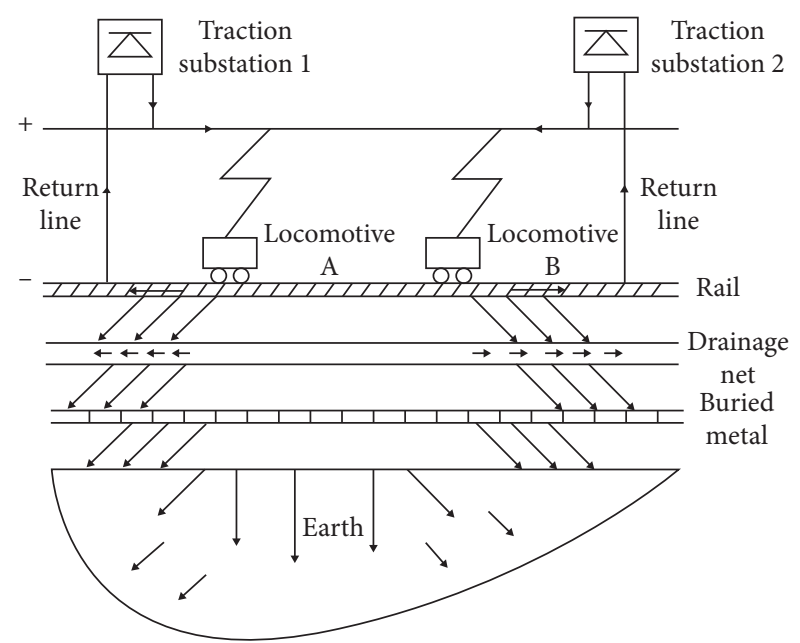

FIgURE 1: Schematic diagram of stray current flow in multilayer structure when two trains are running.

where $V$ is the scalar potential, whose unit is volt and $\rho_{v}$ is the charge density, whose unit is $\mathrm{c} / \mathrm{m}^{3}$.

The scalar potential $V$ is selected as the degree of freedom in the constant flow field, $\nabla^{2} V=0$, which is constant in the field without current source. For soils with different resistivities, the interface satisfies the following boundary conditions:

$$
\left\{\begin{array}{l}
V_{i}=V_{j} \\
\frac{1}{\rho_{i}} \frac{\mathrm{d} V_{i}}{\mathrm{~d} n}=\frac{1}{\rho_{j}} \frac{\mathrm{d} V_{j}}{\mathrm{~d} n}
\end{array}\right.
$$

According to the theory of the constant flow field, the current has continuity in $X, Y$, and $Z$ directions, and then the partial differential equation satisfied by potential in the rectangular coordinate system is as follows:

$$
f(x, y, z)=\frac{\partial}{\partial x}\left(\gamma \frac{\partial V}{\partial x}\right)+\frac{\partial}{\partial y}\left(\gamma \frac{\partial V}{\partial y}\right)+\frac{\partial}{\partial z}\left(\gamma \frac{\partial V}{\partial z}\right),
$$

where $f$ is the position function of the current source. A constant current field can be equivalent to an electrostatic field, so the uniqueness feature can be applied to define the first and second kinds of boundary conditions as follows:

$$
\begin{gathered}
\left.V\right|_{S_{1}}=0, \\
\left.\frac{\partial V}{\partial n}\right|_{S_{2}}=0,
\end{gathered}
$$

where $S_{1}$ is the boundary of infinity, $S_{2}$ is the boundary of the earth and air contact, and $n$ is the direction of the outer normal pointing to the air. Then, the unique solution of the constant flow field can be determined by the above formula. According to the actual situation, the finite element method is adopted and ANSYS software is used to simulate and solve the ground potential distribution $[20,21]$.

The field circuit coupling method is usually used to calculate DC bias of the main transformer in the urban area. 
The transformer is in the city AC power grid, so under normal operation, the transformer with neutral point grounding will inject current into the earth, and the stray current generated in the process of the subway operation will also be injected into the ground. The magnitudes of the two currents are not significantly different, so they will affect each other. Assuming that the number of substations in the power network around the subway is $n$, without considering the $\mathrm{AC}$ action, according to the node voltage equation, the following equation can be obtained:

$$
J=Y U \text {, }
$$

where $U_{1} \sim U_{n}$ is the induced potential of $n$ substation nodes. $J_{1} \sim J_{n}$ is the injected node DC generated by the ground potential gradient. $Y$ is the admittance matrix of the power grid. The $k$-th element in matrix $J$ can be expressed as follows:

$$
J_{k}=\sum_{i=1}^{N} \frac{V_{i k}}{R_{i k}},
$$

where $V_{i k}$ represents the equivalent voltage of the transmission line between substations $i$ and $k$ under the ground potential distribution. $R_{i k}$ represents the resistance of the transmission line between substations $i$ and $k$. The relationship between $V_{i k}$ and the ground potential is as follows:

$$
V_{i k}=\left(U_{B k}-U_{B i}\right) L_{i k} \cos \varphi,
$$

where $U_{B k}$ and $U_{B i}$ are the ground potentials at substations $k$ and $i$, respectively, which can be calculated by formulas (2) (4). $L_{i k}$ is the linear distance between the two stations, $\cos \varphi$ is the angle between the ground potential difference vector and the connecting line between the two stations. According to formulas (6) and (7), the neutral point current of each substation around the subway track is as follows:

$$
I_{S}=Z_{S}^{-1} U_{n},
$$

where $Z_{S}$ represents $n \times n$ order impedance matrix and its diagonal element is composed of $R_{i}^{s}$, which represents substation grounding resistance.

In conclusion, the current of the transformer grounding body can be calculated.

\section{Influencing Factors of DC Current at the Neutral Point of the Main Transformer in the Urban Area}

The problem of transformer DC bias caused by railway operation is not only related to the geoelectric field generated by stray current, but also related to the structure and parameters of the power grid around the metro line. The higher the value of the stray current is, the greater the risk of DC bias will be. Therefore, the geoelectric field caused by the stray current can be taken as the research object $[22,23]$. The calculation of the DC current at the neutral point of the main transformer in the urban area is divided into two parts: one part is the calculation of the geoelectric field and the other part is the calculation of the DC current of the transformer neutral point by combining the known ground electric field with the relevant theory of the power system. Therefore, the influencing factors of the DC current at the neutral point of the main transformer in the urban area can be divided into two categories: influence of the stray current-induced geoelectric field on DC current at the neutral point of the main transformer in the urban area and the influence of the power network structure and the electrical equipment type on the DC current of the main transformer neutral point in the urban area.

\subsection{Influencing Factors of Stray Current-Induced Geoelectric} Field. According to the flow path of the stray current, the factors that affect the stray current-induced earth electric field are the magnitude of the locomotive current, the magnitude of the rail ground transition resistance, the magnitude of the rail longitudinal resistance, the distance of the power supply, and laying down of the drainage network.

According to the power calculation formula $P=U I$, in the case of the same traction power, the locomotive current can be reduced by increasing the supply voltage of the traction transformer power supply, so as to achieve the purpose of reducing stray current. At present, the DC traction power supply voltage of Metro in China is mainly $750 \mathrm{~V}$ and $1500 \mathrm{~V}$. The stray current can be reduced by using $1500 \mathrm{~V}$ traction transformer supply voltage.

The incomplete insulation between the subway track and the ground is the cause of stray current, and the insulation performance of rail directly affects the magnitude of the stray current. When the stray current flows in the rail, underground pipeline, and buried metal, the metal will undergo electrochemical reaction, resulting in different degrees of corrosion of the rail and metal parts [24]. With the growth of the line operation time, the insulation aging phenomenon will inevitably appear between the rail and the ground, and in severe cases, insulation damage may be caused. This will affect the stray current and the distribution of the ground potential. Due to the damage of insulation, the leakage of the stray current is increased, so the rail ground transition resistance is an important influence factor. According to the Technical specification for stray current corrosion protection of Metro [25] (CJJ 49-1992), the transition resistance of the running rail to ground of a new line shall not be less than $15 \Omega \cdot \mathrm{km}$, and that of running line to ground shall be greater than or equal to $3 \Omega \mathrm{km}$.

The induced ground potential of the stray current is largely affected by the longitudinal resistance of the rail. According to Ohm's theorem of the circuit $U=R I$, when the current is constant, the greater the resistance, the greater the voltage. That is to say, the greater the longitudinal resistance of rail is, the greater the potential difference of the ground potential formed by the stray current is, thus affecting the DC current of the neutral point of the main transformer in the urban area.

The action mechanism of the power supply distance on the stray current-induced earth electric field is equivalent to rail longitudinal resistance. In the process of locomotive operation, the farther the power supply distance is, the more 
the stray current will leak into the earth. On the contrary, shortening the power supply distance can reduce the value of the backflow resistance and makes most of the current return from the rail to the negative pole of the traction substation. Therefore, the potential value of the ground electric field will also decrease, and the influence of the grounding transformer around the line will also be reduced. For the drainage network, the function of the drainage network is to provide a low resistance channel for the stray current to prevent the stray current from leaking to other metal structures. The stray current drainage network makes most of the stray current return from the main collection network to the negative pole of the substation, while a small part of the stray current flows back from the drainage network, which greatly reduces the leakage of the stray current.

\subsection{Influencing Factors of Grid Structure and Electrical} Equipment Type. When the stray current-induced geoelectric field is known, the magnitude of the DC current at the neutral point of the main transformer in the urban area depends on the structure of the AC system grid around the subway and the type of power transformer equipment. The relative position between each substation and the subway line determines the magnitude of the potential of the transformer. The stray current is generated by the subway operation, which means that the location of the subway represents that the stray current as a point power supply injects DC current into the location and forms an induced geoelectric field at this location. Therefore, the geoelectric field generated by the stray current is a dynamic one. However, the substations distributed along the subway line remain unchanged for the determined grid structure. Therefore, combined with the power grid structure and the distribution of the ground potential, the DC current of the transformer neutral point around the subway can be obtained. According to the technical guidelines of high-voltage DC grounding electrode, the allowable DC limits of each phase winding of single-phase transformer, three-phase five-column transformer, and three-phase transformer are $0.3 \%, 0.5 \%$, and $0.7 \%$ of their rated current, respectively. It can be seen that the withstand ability of the transformer for DC current depends on the type of power transformer. In addition, in order to reduce the influence of the stray current, the neutral point of some influential power transformers will be equipped with DC isolation devices such as capacitors and resistors. However, the installation of capacitance and resistance changes the original grounding performance of the transformer, changes the grid structure to a certain extent, and thus affects the neutral point current of the urban main transformer.

\section{Example Analysis}

Urumqi Metro No. 1 passes through 16 stations, and there are four $220 \mathrm{kV}$ substations nearby, namely, Sangong substation, Laomancheng substation, Bahuliang substation, and Miquan substation. The specific distribution situation of substations and metro lines is shown in Figure 2. The details of the substation grounding mode and the distance between the substation and the subway track are shown in Table 1.

When Urumqi line 1 subway is running, it will inevitably affect the transformers along line 1 . Here, we focus on the influence of line 1 on Sangong substation, which is the nearest to the subway line. Therefore, taking "Xuanrendun station-Yingbin intersection station" as the center line, including Sangong substation, a cube model with length, width, and depth of $6 \mathrm{~km}$ was established by using ANSYS, in which the length represents the length of the metro line and the depth represents the depth of the soil layer. The parameters of the soil model are shown in Table 2.

The distance between traction substation 1 and traction substation 2 is $5 \mathrm{~km}$, the distance between locomotive A and traction substation 1 is $3.5 \mathrm{~km}$, and the distance between locomotive $\mathrm{B}$ and traction substation 1 changes in the range of $0.5-2.5 \mathrm{~km}$. The magnitudes of values and ranges of other parameters are shown in Table 3.

The State Grid Urumqi power supply company carried out DC online monitoring for No. 1 main transformer and No. 2 main transformer of $220 \mathrm{kV}$ Sangong substation and obtained the maximum value of the daily neutral point DC of No. 1 main transformer and No. 2 main transformer of Sangong substation from March 24 to April 3, 2018, as shown in Figure 3.

According to the test results, there is no obvious correlation between the DC current curve of the $110 \mathrm{kV}$ side neutral point of No. 1 main transformer of Sangong substation and the load curve of the power supply of Metro Line 1 ; thus, the influence of the stray current of Metro Line 1 on the No. 1 main transformer of Sangong station is not obvious. From 10:00 to 16:00, on a working day, the DC current at the $220 \mathrm{kV}$ side of No. 2 main transformer of Sangong substation changes very fast and has large amplitude. In other time periods, the amplitude of the DC current at the neutral point of No. 2 main transformer is obviously small, with no change in positive and negative poles, which is related to the power supply load curve of Metro Line 1.

The straight-line physical distance between Urumqi Metro Line 1 and $220 \mathrm{kV}$ Sangong substation is about $2 \mathrm{~km}$; the models of two locomotives braking at the same time (condition 1), two locomotives accelerating at the same time (condition 2), and one locomotive slowing down and one locomotive accelerating (condition 3) are established, respectively. According to the surface potential of the model constructed, it can be seen that the range of the ground potential of Sangong substation under the three working conditions is shown in Table 4.

According to the calculation model of "geomagnetic field-transformer magnetic bias DC," combined with the magnitude of the ground potential of Sangong station under three working conditions, the value range of the neutral point current of Sangong station under three working conditions can be obtained, as shown in Table 5 .

Combined with the value range of the neutral point current and the DC monitoring waveform of the neutral point in Sangong substation under different working conditions, it can be seen that the neutral point current at $220 \mathrm{kV}$ side of the main transformer of Sangong station is 


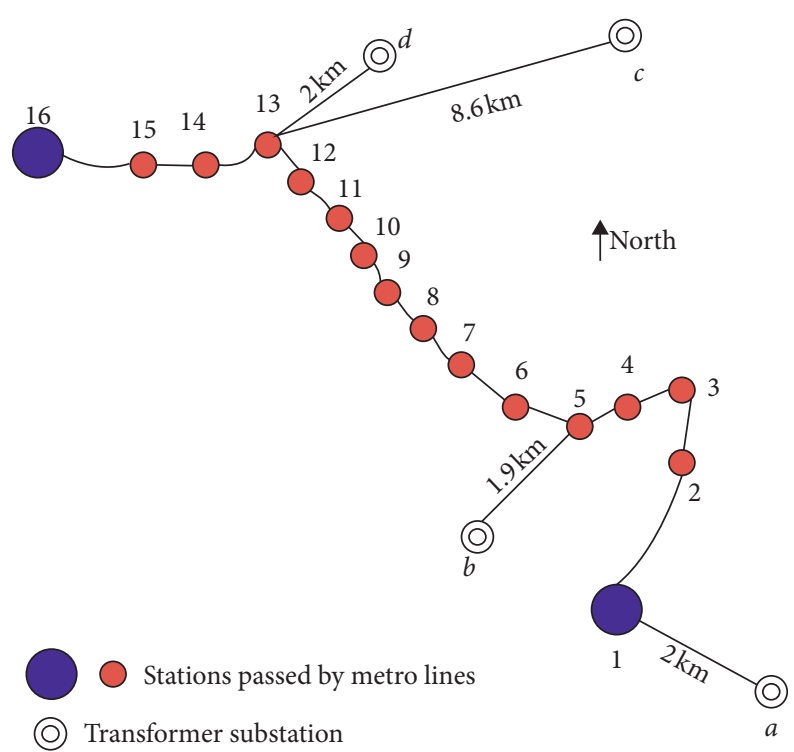

Figure 2: Location of substation and Metro Line 1.

TABLE 1: List of distances between Metro Line 1 and substation.

\begin{tabular}{lclc}
\hline Serial number & Transformer substation & Neutral grounding of main transformer & Distance $(\mathrm{km})$ \\
\hline 1 & $220 \mathrm{kV}$ Bahuliang substation & $110 \mathrm{kV}$ neutral point grounding of No. 1 main transformer & $220 \mathrm{kV}$ neutral point grounding of No. 2 main transformer \\
& & $110 \mathrm{kV}$ neutral point grounding of No. 1 main transformer & 2.0 \\
2 & $220 \mathrm{kV}$ Laomancheng substation & $220 \mathrm{kV}$ neutral point grounding of No. 2 main transformer & 1.9 \\
3 & $220 \mathrm{kV}$ Miquan substation & $110 \mathrm{kV}$ neutral point grounding of No. 1 main transformer & $220 \mathrm{kV}$ neutral point grounding of No. 2 main transformer \\
& & $110 \mathrm{kV}$ neutral point grounding of No. 1 main transformer & 8.6 \\
4 & $220 \mathrm{kV}$ Sangong substation & $220 \mathrm{kV}$ neutral point grounding of No. 2 main transformer & 1.3 \\
\hline
\end{tabular}

TABLE 2: Soil parameters of complex model.

\begin{tabular}{lcc}
\hline Number of layers & Layer depth $(\mathrm{m})$ & Resistivity $(\Omega \cdot \mathrm{m})$ \\
\hline 1 & 6 & 30 \\
2 & 14 & $2.1^{*} 10^{-7}$ \\
3 & 150 & 250 \\
4 & 290 & 1070 \\
5 & 1120 & 7200 \\
6 & 4155 & 27.5 \\
7 & 20 & 90 \\
8 & 15 & 25 \\
9 & 175 & 22 \\
10 & 55 & 2 \\
\hline
\end{tabular}

TABLE 3: Model parameter value magnitude/range details.

\begin{tabular}{lc}
\hline Influence factor & Value size $/$ range \\
\hline Longitudinal resistance of rail $R_{g}$ & $0.035 \Omega / \mathrm{km}$ \\
Longitudinal resistance of buried metal $R_{m}$ & $0.01 \Omega / \mathrm{km}$ \\
Earth longitudinal resistance $R_{d}$ & $0.001 \Omega / \mathrm{km}$ \\
Longitudinal resistance of drainage network $R_{p}$ & $0.001 \Omega / \mathrm{km}$ \\
Transition conductance between rail and drainage network $G_{1}$ & $0.1 \mathrm{~S} / \mathrm{km}$ \\
Transition conductance between earth and buried metal $G_{2}$ & $1 / 3 \mathrm{~S} / \mathrm{km}$ \\
Distance between train B and traction substation 1 & $0.5 \mathrm{~km}-2.5 \mathrm{~km}$ \\
Locomotive current collection & $1000-3000 \mathrm{~A}$ \\
\hline
\end{tabular}




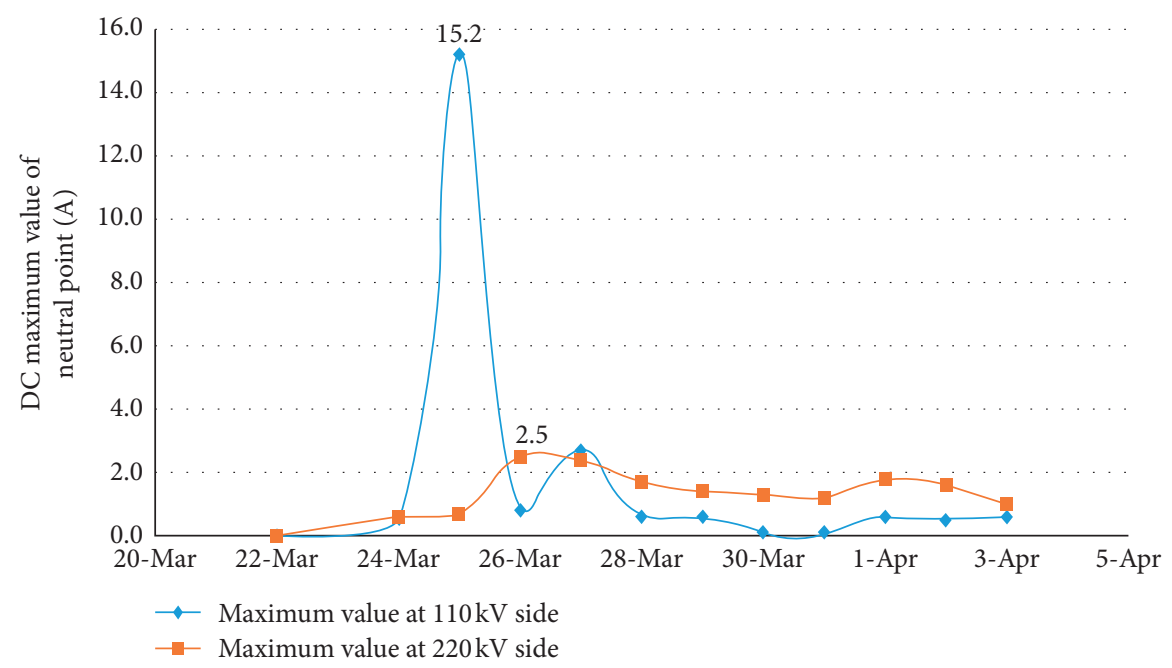

Figure 3: Monitoring of neutral point of No. 1 and No. 2 main transformer in Sangong substation.

TABLE 4: Potential values of Sangong substation under different working conditions.

\begin{tabular}{lccc}
\hline Metro operation conditions & \multicolumn{3}{c}{ Possible value of grounding potential (V) } \\
\hline Condition 1 & -0.3333 & 2.8887 & 6.1151 \\
Condition 2 & -0.9823 & 4.1818 & 9.3448 \\
Condition 3 & -0.7763 & 3.3055 & 7.3872 \\
\hline
\end{tabular}

TABLe 5: Possible values of neutral point current of Sangong substation under different working conditions.

\begin{tabular}{|c|c|c|c|c|}
\hline \multirow{2}{*}{$\begin{array}{l}\text { Metro operation conditions } \\
\text { Condition } 1\end{array}$} & \multicolumn{4}{|c|}{ Possible values of neutral point current (A) } \\
\hline & -0.0825 & 0.7222 & 1.5288 & 2.3336 \\
\hline Condition 2 & -0.2456 & 1.04545 & 2.3362 & 3.627 \\
\hline Condition 3 & -0.1941 & 0.8264 & 1.8468 & 2.8673 \\
\hline
\end{tabular}

between $-0.0825 \mathrm{~A}$ and $3.627 \mathrm{~A}$, which is consistent with the monitored range of daily maximum current data of 0.6 A-2.5 A. Moreover, the change in the DC current data of No. 2 main transformer of Sangong substation is consistent with the characteristics of the DC bias magnetism caused by the load of power supply system of Metro Line 1. The DC current of $2.5 \mathrm{~A}$ is the maximum value in the monitoring data. Compared with the maximum value of $3.627 \mathrm{~A}$ in the simulation data, the current appears in condition 2, that is, when two locomotives are accelerating at the same time. It shows that the DC current at the neutral point of the transformer will get the maximum value when the two locomotives are accelerating at the same time.

In order to deeply understand the distribution and relationship of the ground potential among the three working conditions, the geoelectric field model under the three working conditions is established by using ANSYS, and the parameters are selected according to Table 3, and the results as shown in Figure 4 are obtained.

In order to more intuitively represent the distribution of the transformer neutral point current caused by stray current ground potential distribution, statistical characteristics of the transformer neutral point current distribution under seven distances of $500 \mathrm{~m}, 800 \mathrm{~m}, 1000 \mathrm{~m}$, $1500 \mathrm{~m}, 1800 \mathrm{~m}, 2000 \mathrm{~m}$, and $2500 \mathrm{~m}$ are analyzed, as shown in Table 6.

According to Table 6, the distribution trend of the transformer neutral point current is roughly the same under the condition of double locomotive deceleration braking or traction operation, which shows that the farther away they are from the subway track, the greater the absolute value of the neutral point current. The statistical value of the braking operation current of double locomotives is less than that of double locomotive traction operation at the same time. For the distribution of the current under the condition that one locomotive undergoes braking and the other locomotive undergoes traction, the closer the distance is to the subway track, the greater the absolute value of the neutral point current. Within $800 \mathrm{~m}$ from the subway track, the positive maximum current value is higher than the positive maximum value under the condition of dual locomotive traction or braking at the same time. The absolute value of the negative maximum current is lower than that of the double locomotive traction or braking when the distance is more than $2 \mathrm{~km}$ away from the subway track. When the distance is between $800 \mathrm{~m}$ and $2 \mathrm{~km}$ away from the subway track, the 
1

Nodal solution

Step $=1$

Sub $=1$

Time $=1$

Volt

(AVG)

Rsys $=0$

$\mathrm{Smn}=-0.333774$

Smx $=28.67$

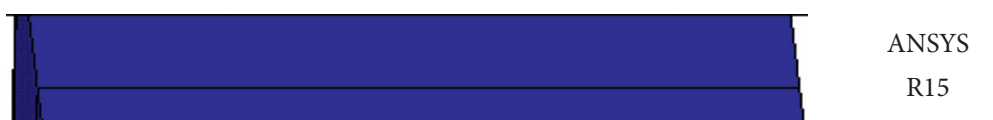

FEB 23202

16:29:3
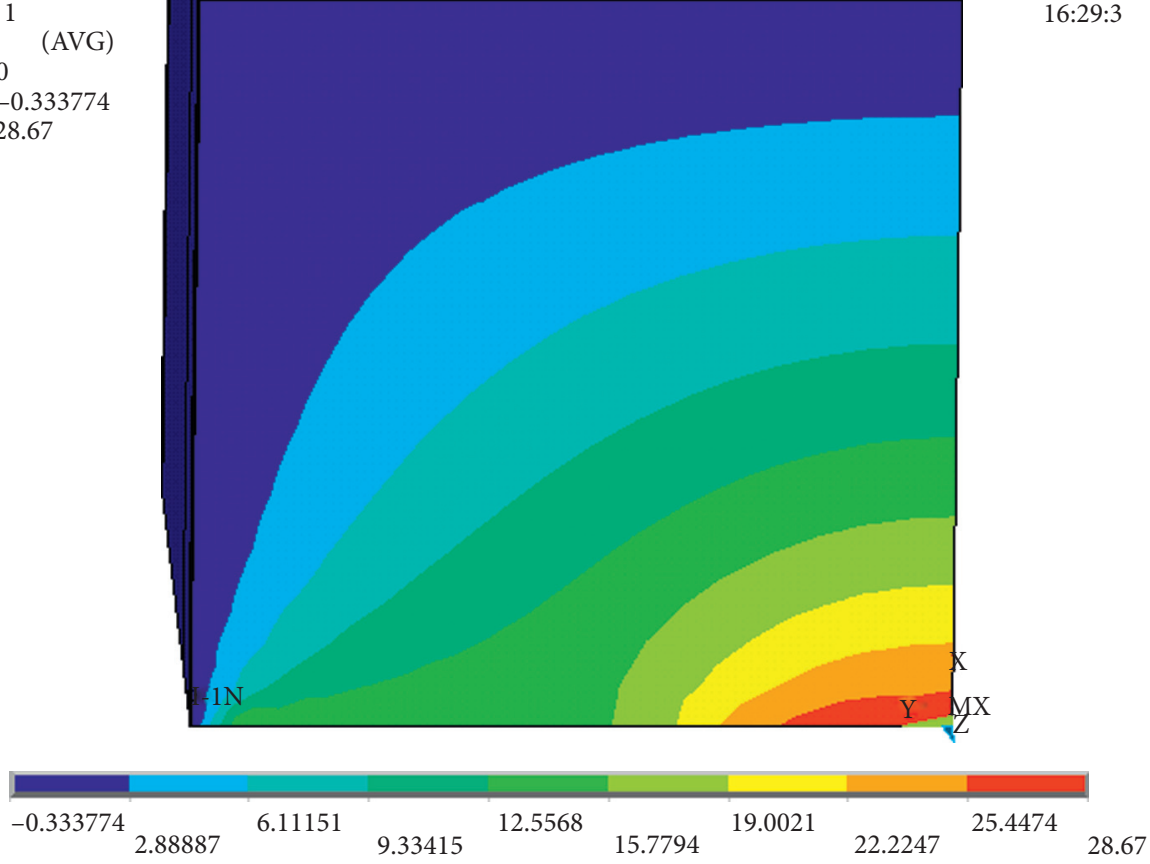

(a)

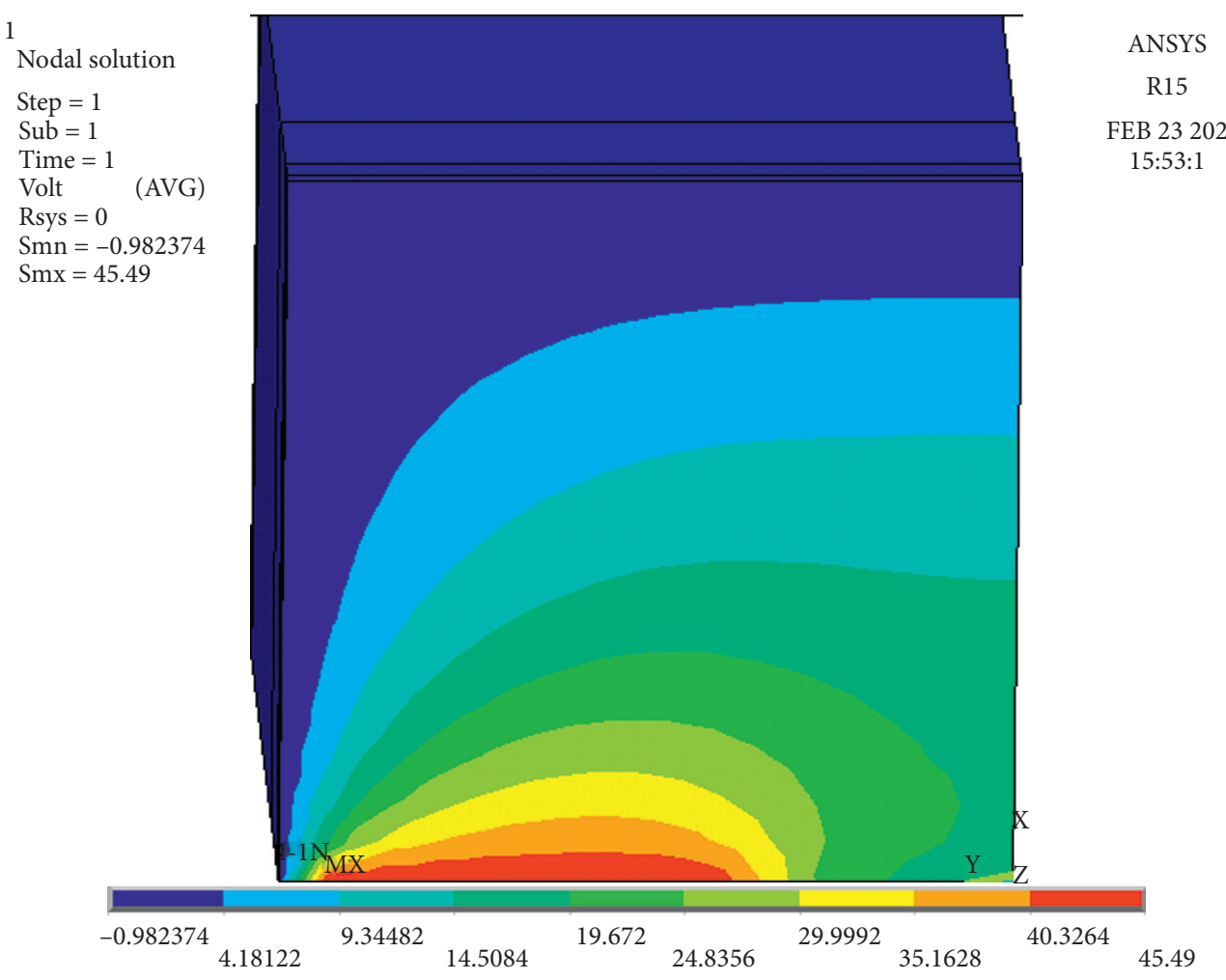

(b)

Figure 4: Continued. 


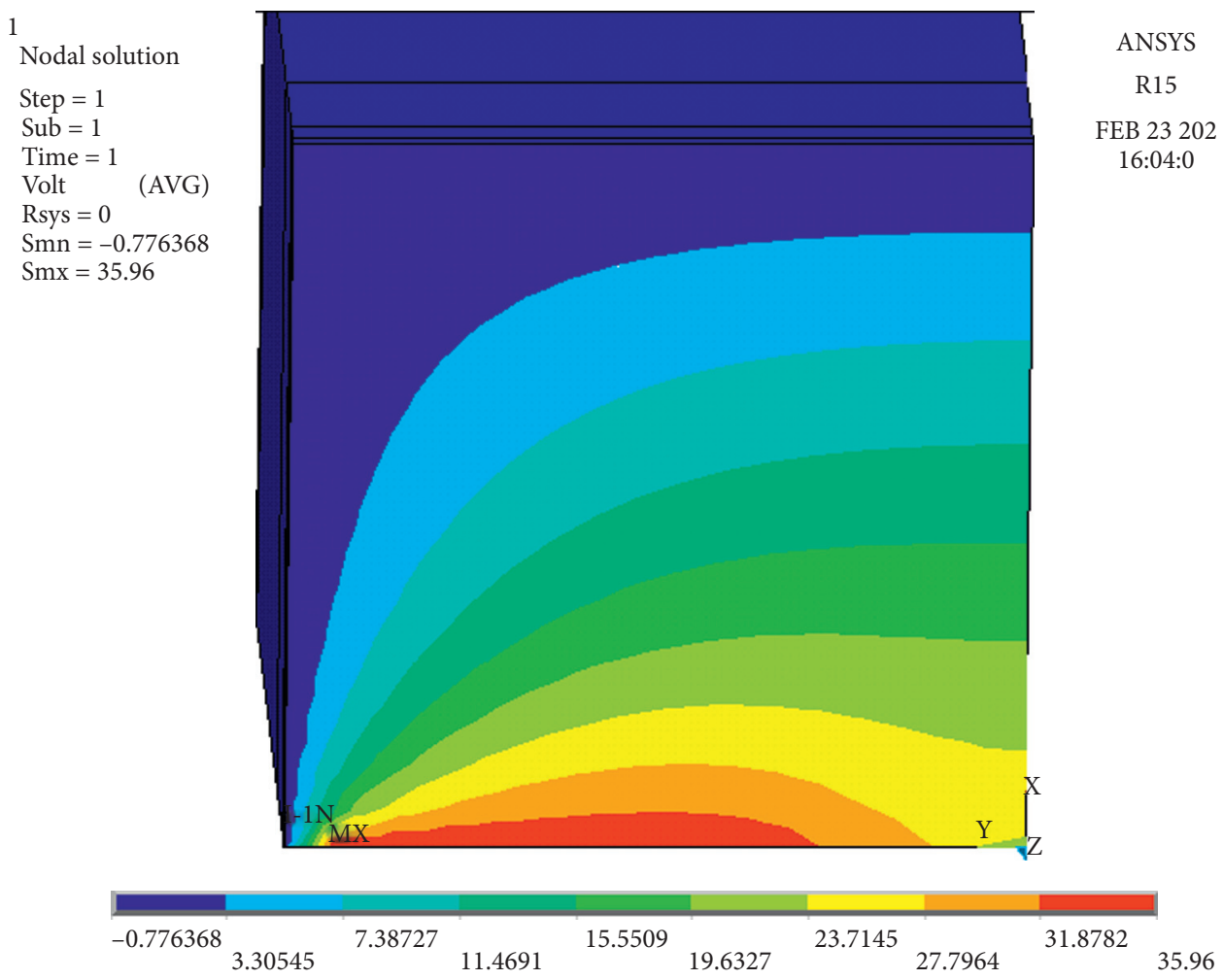

(c)

Figure 4: Distribution of metro stray current-induced geoelectric field under three working conditions. (a) Condition 1. (b) Condition 2. (c) Condition 3.

TABLE 6: Statistical table of distribution of maximum neutral point current of transformers under various operating conditions.

\begin{tabular}{|c|c|c|c|c|c|c|c|c|}
\hline Metro operation conditions & Distance $(\mathrm{m})$ & 500 & 800 & 1000 & 1500 & 1800 & 2000 & 2500 \\
\hline \multirow[b]{2}{*}{ Condition 1} & Maximum forward cur & 6.485 & 7.015 & 7.29 & 7.715 & 8.253 & 8.535 & 8.99 \\
\hline & Maximum neg & -3.283 & -3.228 & -3.268 & -3.613 & -4.575 & -5.168 & -6.485 \\
\hline \multirow{2}{*}{ Condition 2} & Maximum forward current (A) & 4.675 & 4.702 & 4.808 & 5.483 & 7.298 & 8.488 & 11.37 \\
\hline & Maximum negative current (A) & -8.595 & -9.668 & -10.318 & -11.708 & -13.025 & -13.843 & -15.59 \\
\hline \multirow{2}{*}{ Condition 3} & Maximum forward current (A) & 7.168 & 7.042 & 6.893 & 6.268 & 5.713 & 5.263 & 3.868 \\
\hline & Maximum negative current (A) & -6.055 & -6.163 & -6.143 & -5.765 & -5.313 & -4.923 & -3.645 \\
\hline
\end{tabular}

maximum value of positive current is between the maximum value of the positive current under the condition of dual locomotive traction and the maximum value of the positive current under the condition of dual locomotive braking at the same time. Therefore, it can be concluded that the transformer neutral point current when two locomotives run in different ways is not equal to the linear superposition of the two locomotives in the case of braking or traction at the same time.

\section{Epilogue}

The phenomenon of DC bias of the main transformer in the urban area caused by subway operation is increasing day by day, and the influence of the stray current becomes a problem that cannot be ignored. Based on the actual calculation example, a model was built by using ANSYS software and the range of the DC current at the neutral point of the Sangong transformer was obtained by combining the circuit theory knowledge. The correctness of the model is verified by comparing with the measured data. On this basis, it can be concluded that the transformer neutral point current when two locomotives run in different ways is not equal to the linear superposition of the two locomotives in the case of braking or traction at the same time. The influence of current distribution will compensate for each other when the two locomotives run in different conditions. The research can provide useful reference for the calculation and treatment of DC bias of the main transformer in the urban area under the action of stray current.

\section{Data Availability}

In order to conduct further research, the paper data cannot be shared temporarily. 


\section{Conflicts of Interest}

The authors declare no potential conflicts of interest with respect to the research, authorship, and/or publication of this article.

\section{References}

[1] Z. Pan, X. Wang, B. Tan et al., "Potential compensation method for restraining the DC bias of transformers during HVDC monopolar operation," IEEE Transactions on Power Delivery, vol. 31, no. 1, pp. 103-111, 2016.

[2] R. Zeng, Z. Yu, B. Zhang, and B. Niu, "Study on restraining DC neutral current of transformer during HVDC monopolar operation," IEEE Transactions on Power Delivery, vol. 26, no. 4, pp. 2785-2791, 2011.

[3] Z. Pan, L. Zhang, X. Wang et al., "HVDC ground return current modeling in AC systems considering mutual resistances," IEEE Transactions on Power Delivery, vol. 31, no. 1, pp. 165-173, 2016.

[4] K. Zheng, D. Boteler, R. J. Pirjola et al., "Effects of system characteristics on geomagnetically induced currents," IEEE Transactions on Power Delivery, vol. 29, no. 2, pp. 890-898, 2013.

[5] H. Zhu and T. J. Overbye, "Blocking device placement for mitigating the effects of geomagnetically induced currents," IEEE Transations on Power Systems, vol. 30, no. 4, pp. 20812089, 2015.

[6] S. Marsal and J. M. Torta, "Quantifying the performance of geomagnetically induced current models," Space Weather, vol. 17, no. 7, pp. 941-949, 2019.

[7] D. Wang and C. Liu, "Combination optimization configuration method of capacitance and resistance devices for suppressing DC bias in transformers," Energies, vol. 12, p. 1813, 2019.

[8] Y. Pang, Research on Stray Current of Urban Rail Transit, Southwest Jiaotong University, Chengdu, China, 2008.

[9] G. Du, J. Wang, X. Jiang, D. Zhang, L. Yang, and Y. Hu, "Evaluation of rail potential and stray current with dynamic traction networks in multitrain subway systems," IEEE Transactions on Transportation Electrification, vol. 6, no. 2, pp. 784-796, 2020.

[10] K. Yu, Y. Ni, X. Zeng, P. Peng, X. Fan, and Y. Leng, "Modeling and analysis of transformer DC bias current caused by metro stray current," IEEJ Transactions on Electrical and Electronic Engineering, vol. 15, no. 10, 2020.

[11] Z. Pan, L. Zhang, B. Tan et al., "Theoretical derivation and numerical analysis for grounding computation of horizontal multi-layer soil," High Voltage Engineering, vol. 37, no. 4, pp. 860-866, 2011.

[12] Z. Ma, X. Li, and D. Zhong, "Network algorithm to analyze effects of DC transmission ground current on AC system," Guangdong Electric Power, vol. 18, no. 12, pp. 4-8, 2005.

[13] L. Mou, W. Shi, and M. Zhang, "Metro stray current distribution with current drainage net," Journal of the China Railway Society, vol. 29, no. 3, pp. 45-49, 2007.

[14] G. Xu, Research and Design of Stray Current Protection Scheme for DC Traction Power Supply System, Southwest Jiaotong University, Chengdu, China, 2003.

[15] J. Wang, L. Zhao, and Q. Yuan, "Mathematical model of distribution of metro stray current," Chinese Journal of Engineering Mathematics, vol. 26, no. 4, pp. 571-576, 2009.

[16] K. Yu, F. Zhu, G. Liu et al., "Simulation of subway stray current based on CDEGS," Electric Railway, vol. 34, no. 6, pp. 44-48, 2014.
[17] D. Zhang, J. Liu, Y. Xie et al., "Evaluation and analysis of dynamic stray current in DC metro system," Urban Mass Transit, vol. 20, no. 4, pp. 67-71, 2017.

[18] K. Guo, "Research on location selection model of distribution network with constrained line constraints based on genetic algorithm," Neural Computing and Applications, vol. 32, no. 1, pp. 1-11, 2019.

[19] W. Elsayed, M. Elhoseny, S. Sabbeh, and A. Riad, "Selfmaintenance model for wireless sensor networks," Computers \& Electrical Engineering, vol. 70, pp. 799-812, 2018.

[20] M. R.-A. Rizk, A. E. Hassanien, and M. Elhoseny, "A multiobjective transportation model under neutrosophic environment," Computers and Electrical Engineering, vol. 69, pp. 705-719, 2018.

[21] X. Wang, Y. Liu, and K. R. Choo, "Fault tolerant multi-subset aggregation scheme for smart grid," IEEE Transactions on Industrial Informatics, vol. 1, 2020.

[22] X. Hu, P. Ma, B. Gao, and M. Zhang, "An integrated step-up inverter without transformer and leakage current for gridconnected photovoltaic system," IEEE Transactions on Power Electronics, vol. 34, no. 10, pp. 9814-9827, 2019.

[23] W. Zhu, Z. Zhang, D. Chen et al., "Interfacial voids trigger carbon-based, all-inorganic $\mathrm{CsPbIBr}_{2}$ perovskite solar cells with photovoltage exceeding $1.33 \mathrm{~V}$," Nano-Micro Letters, vol. 12 , no. 1 , pp. $1-14,2020$.

[24] L. Cai, J. Wang, Y. Fan et al., "Influence of the track-to-earth resistance of subway on stray current distribution," High Voltage Engineering, vol. 41, no. 11, pp. 3604-3610, 2015.

[25] CJJ 49-1992, Technical Specification for Stray Current Corrosion Protection of Metro, China Standard Press, Beijing, China, 1992. 